\title{
Hydrophilic-coated catheter appreciation study in a pediatric population
}

\author{
Andréanne Boucher, MD; Jonathan Cloutier, MD; Sylvie Lebel, RN; Micheline Hamel, RN; \\ Pascale Lamontagne, RN; Stéphane Bolduc, MD, FRCSC
}

\section{Abstract}

Objective: The objective of the paper was to compare the satisfaction of hydrophilic-coated catheters (HC) (SpeediCath, Coloplast Canada, Mississauga, $\mathrm{ON}$ ) versus uncoated catheters in a pediatric neurogenic bladder population, in order to identify a target group for HC. The main hypothesis was that our patients, with regard to their limitations, might have difficulties using the $\mathrm{HC}$.

Material and methods: A comparative prospective study was initiated in one pediatric rehabilitation centre. Out of the 39 patients who tried the $\mathrm{HC}$ during a routine clinic visit, 31 patients/parents accepted to participate in a 1-week trial and to answer a satisfaction questionnaire. Their medical records were reviewed for age, neurological disease, intellectual deficit, impaired dexterity and method of catheterization (Mitrofanoff/urethra).

Results: Thirty of the 31 patients answered the satisfaction questionnaire. The median age for the 30 patients was 13.5 years (range $6-20$ years). Of these patients, 19 were females (63\%), 26 performed self-catheterization (87\%), and 6 had Mitrofanoff (20\%). Ten children (33\%) would be ready to proceed with $\mathrm{HC}$ and all 10 children would receive catheterization by the urethra. Of these, 9 were females $(90 \%), 8$ used compact-HC $(80 \%)$ and all were selfsufficient. Patients using compact-HC would continue with this catheter. In the patient comments, males catheterizing per-urethra and patients using a continent stoma requiring long catheters had problems with the excess of lubricant.

Conclusion: Most children preferred their usual uncoated catheter and would not change for HC. Female patients catheterizing perurethra with a compact-HC seem to benefit most from this catheter.

\section{Can Urol Assoc J 2010;4(6):E150-E154}

\section{Résumé}

Objectif : L'étude visait à comparer le niveau de satisfaction avec les cathéters à enrobage hydrophile (SpeediCath, Coloplast Canada, Mississauga, Ontario) et avec les cathéters sans enrobage chez des enfants avec vessie neurogène, afin de cerner un groupe cible pour le cathéter à enrobage hydrophile. La principale hypothèse de l'étude était que les participants pourraient éprouver des difficultés avec ce dernier, en fonction de leurs limites physiques. Matériel et méthodes : On a mis sur pied une étude prospective de comparaison dans un centre de réadaptation pédiatrique. Sur les 39 patients ayant testé le cathéter à enrobage hydrophile pendant une visite de routine, 31 patients et leurs parents ont accepté de participer à un essai d'une semaine et de répondre à un questionnaire sur leur niveau de satisfaction. Les dossiers médicaux ont été passés en revue afin de vérifier l'âge des patients, la présence d'un trouble neurologique, d'un déficit intellectuel et d'une anomalie au niveau de la dextérité et la méthode de cathétérisme (technique de Mitrofanoff/voie urétrale).

Résultats : Trente des 31 patients ont rempli le questionnaire sur leur niveau de satisfaction. L'âge médian des 30 patients était de 13,5 ans (6 à 20 ans). De ces patients, 19 étaient des filles (63\%), 26 ont réalisé eux-mêmes le cathétérisme (87\%), et la technique de Mitrofanoff a été utilisée dans 6 cas (20\%). Dix enfants (33\%) seraient prêts à utiliser un cathéter à enrobage hydrophile et ces 10 enfants auraient recours à un cathétérisme par voie urétrale. De ce groupe, 9 étaient des filles (90\%), 8 ont eu recours à un cathéter compact à enrobage hydrophile (80\%) et tous étaient auto-suffisants. Les patients qui ont utilisé un cathéter compact à enrobage hydrophile poursuivraient avec ce type de cathéter. Dans les commentaires des patients, les garçons ayant utilisé un cathétérisme par voie urétrale et les patients ayant eu recours à une stomie continente nécessitant un long cathéter ont signalé des problèmes liés à l'excès de lubrifiant.

Conclusion : La plupart des enfants ont préféré leur cathéter non enrobé habituel et ne passeraient pas à un cathéter à enrobage hydrophile. Les filles ayant subi un cathétérisme par voie urétrale avec un cathéter compact à enrobage hydrophile semblent tirer le plus d'avantages de ce type de cathéter.

\section{Introduction}

Intermittent catheterization was used routinely for urinary retention more than 100 years ago and was unfortunately forgotten. Clean intermittent catheterization $(\mathrm{CIC})$ was reintroduced by Lapides in 1972, which was an important revolution for patients with neurogenic bladder. ${ }^{1}$ It has been life-saving by reducing the risk of upper urinary tract deterioration and urosepsis. ${ }^{2}$ In 1983, a low-friction hydrophilic-coated catheter (HC) was introduced. ${ }^{3}$ It had a layer of polymer coating, bound to the catheter surface. The polymer absorbs and binds water to the catheter, resulting in a thick, smooth and slippery surface. ${ }^{4}$ SpeediCath (Coloplast, Mississauga, $\mathrm{ON}$ ) is a brand of these catheters, and it also has the advantage of being ready-to-use (no need 
for water). Previous studies have demonstrated its efficacy in comparison with uncoated-catheters. ${ }^{2,4}$ Unfortunately, this catheter is more expensive and single use. Only one study was performed in the pediatric population; ${ }^{5}$ other studies were performed in adults only. These studies did not try to find a target group for this product.

The objective of this study was to compare the satisfaction of $\mathrm{HC}$ (with the SpeediCath) versus usual uncoated catheters in a pediatric population presenting with myelomeningocele or spinal cord injury, in order to identify a target group for this HC. A pilot study performed at our centre in 2007, with a small sample of patients, was not encouraging. Most children and parents did not like the HC. The main hypothesis of this study is that our patient population (with its inherent limitations) might have difficulties using the HC.

\section{Materials and methods}

\section{The study design}

A comparative prospective study, approved by the local ethics committee, was initiated. We recruited pediatric patients with neurogenic bladder. The patients agreed to try the HC for 1 week and to answer a questionnaire. The participants catheterized themselves or a parent/tutor performed it, according to their usual procedure. They tried the catheter at home, with no nurse present during the trial.

\section{Participants}

From February 2008 to February 2009, in one pediatric rehabilitation centre, there were 51 patients on CIC. Forty-four children came to the centre for their routine visit during this period; of these, 39 patients agreed to try the HC. During this routine visit, they were introduced to the $\mathrm{HC}$ and a nurse explained how to open and manipulate it. Although many patients/parents did not find this initial attempt to be a positive experience, 31 of the 39 patients/parents still agreed to participate in the 1-week trial. They either had myelomeningocele or spinal cord injury and all needed to perform $\mathrm{CIC}$ to empty their bladder. There were no specific exclusion criteria. Their medical records were reviewed for age, neurological disease, intellectual deficit, impaired dexterity (evaluated by professionals in the multidisciplinary clinic) and method of catheterization (Mitrofanoff/urethra). All participants gave their oral informed consent before being enrolled in this study.

\section{Catheters}

The reference catheter was the type of material they used before trying the $\mathrm{HC}$, including different types of typical uncoated catheters of 20 to $40 \mathrm{~cm}$ long. In the study, they used SpeediCath Compact or SpeediCath (the short version for females [except for females with Mitrofanoff] and the long version for males) for 1 week. The SpeediCath Compact version was introduced after the recruitment began. Once it became available to the female participants, they all chose this compact version. The HCs were supplied to patients at no cost to them. These newly available HCs are disposable and pre-lubricated. The compact version is for women who catheterize by the urethra. It has a telescopic design and its total length is $14.3 \mathrm{~cm}$ including the handle, and $9 \mathrm{~cm}$ before opening it (Fig. 1).

\section{Questionnaire}

All patients received a questionnaire and the child or the parent had to answer it. The nurse explained the questions. The questionnaire was translated to French and adapted from a previously reported study by Taskinen and colleagues. ${ }^{5}$ It had 10 questions about package opening, ease of insertion and withdrawal, comfort, adaptation, $\mathrm{ClC}$ regularity, preparation and $\mathrm{CIC}$ time (approximation by patient) and the need for other materials to perform the CIC. They had to compare the $\mathrm{HC}$ to their usual catheter and to rate their satisfaction. Finally, respondents were asked to comment on

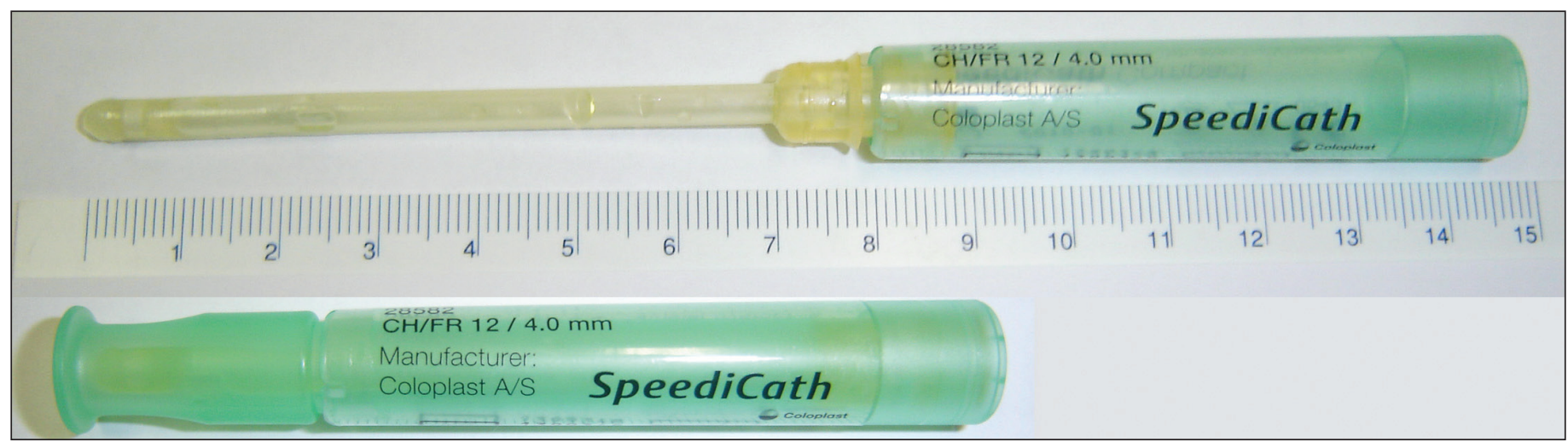

Fig. 1. The SpeediCath Compact catheter as it looks when opened and ready-to-use (upper) and before opening (lower). 
Boucher et al.

whether they would continue to use the $\mathrm{HC}$ and to provide any additional comments. Seven patients did not return the questionnaire and were contacted by phone. They were asked if they would continue to use the $\mathrm{HC}$ and they were free to provide any extra comments.

\section{Results}

Of the 31 patients who entered the 1 -week trial, 30 answered the satisfaction questionnaire, 23 returned the questionnaire and 7 patients were contacted by phone. Of the 30 patients included in the analysis, 11 were males and 19 were females. The median age was 13.5 years old (range 6-20). Twenty-six patients were on self-catheterization and $\mathrm{CIC}$ was performed by a parent in the remaining 4 patients. In our population, 22 had spina bifida (73\%) and 8 had spinal cord injury $(27 \%)$. Five patients had an intellectual deficit (17\%) ( 3 were mild on self-CIC; 2 were moderate with the parent who performed the $\mathrm{CIC}$ ). Nine patients had an impaired fine dexterity $(30 \%)$ and $\mathrm{CIC}$ was performed by the parent in 3 of them. Six patients (20\%) performed CIC by a Mitrofanoff; all 6 patients were female.

\section{Questionnaire results}

Of the 30 questionnaires, $17(57 \%)$ were answered by the patient and 13 by a parent. The 7 patients/parents who answered over the phone were not included in the results for the specific comparison questions (they were only asked whether or not they would continue to use the HC). The median duration of testing was 7 days (range 1-12) and included only patients who completed the questionnaire. Between $61 \%$ and $87 \%$ found their usual catheter adequate based on the different evaluation criteria (Fig. 2). The percentage of patients that did not answer each question was between $8 \%$ and $35 \%$. Respondents compared their usual catheter to the HC (Fig. 3). None of the patients rated the HC better than their usual catheter. Most respondents found the ease of insertion and adaptation to be worse using the $\mathrm{HC}$. Fifteen patients $(50 \%)$ noted that the $\mathrm{HC}$ was too slippery during the manipulation and insertion. The catheter was too stiff in $10 \%$ of the respondents (3/30). The HC had comparable results regarding preparation time (mean: 2 minutes in both) and catheterization time (3.3 minutes $\mathrm{HC}$ vs. 3.8 minutes usual product) compared to their usual catheter.

At the end of the trial, 10 patients (33\%) would be ready to change their actual catheter for the HC. Of these patients, 1 was a male (by urethra) and 9 were females. All the females in the study who had tried the Speedicath Compact (8/8) would be ready to switch to it from their original catheter (Table 1). Of the 5 female patients who tried the short HC per-urethra (not the compact telescopic design), only 1 patient wanted to continue using it.

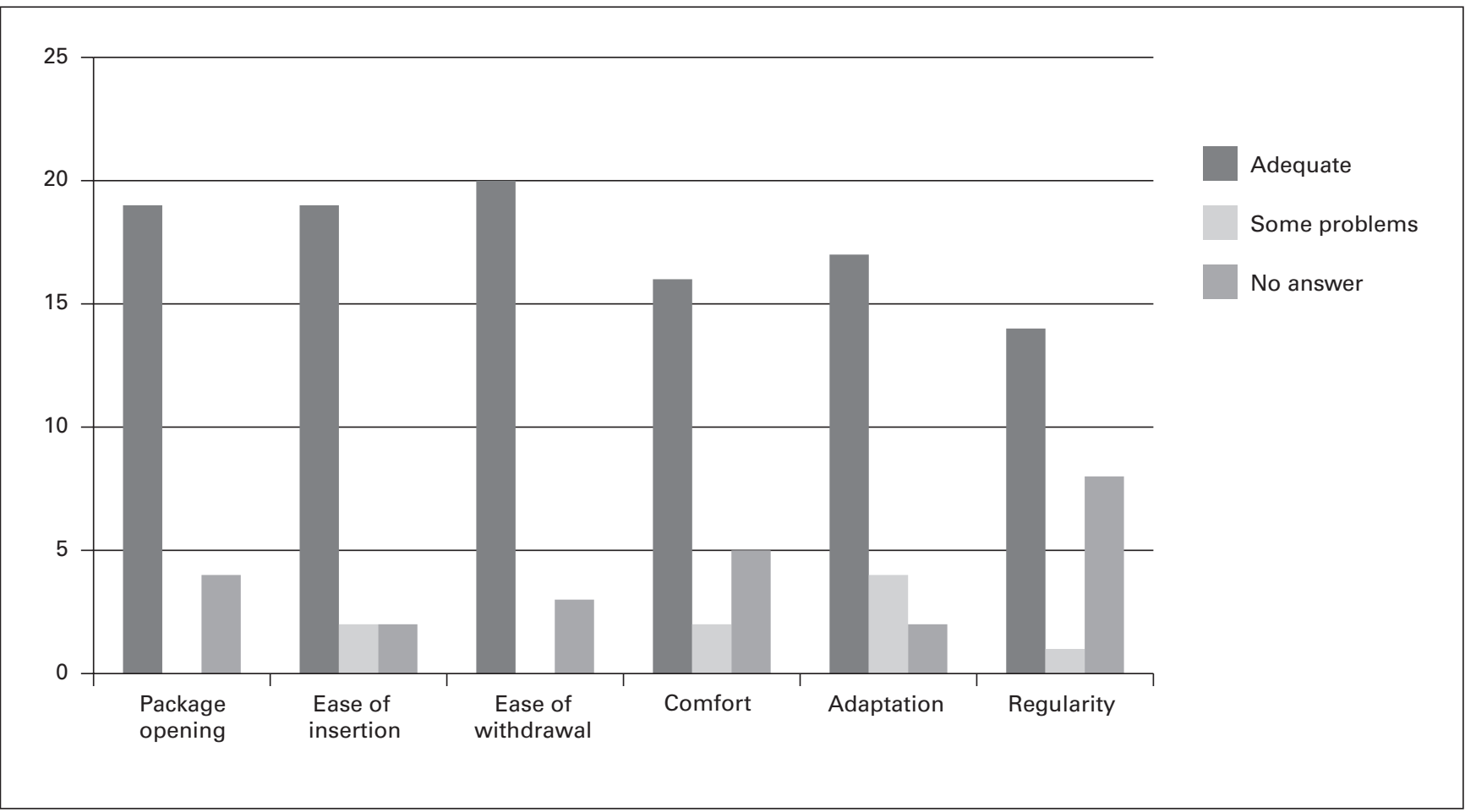

Fig. 2. Evaluation of their usual product. Number of response to each question on 23 questionnaires. 


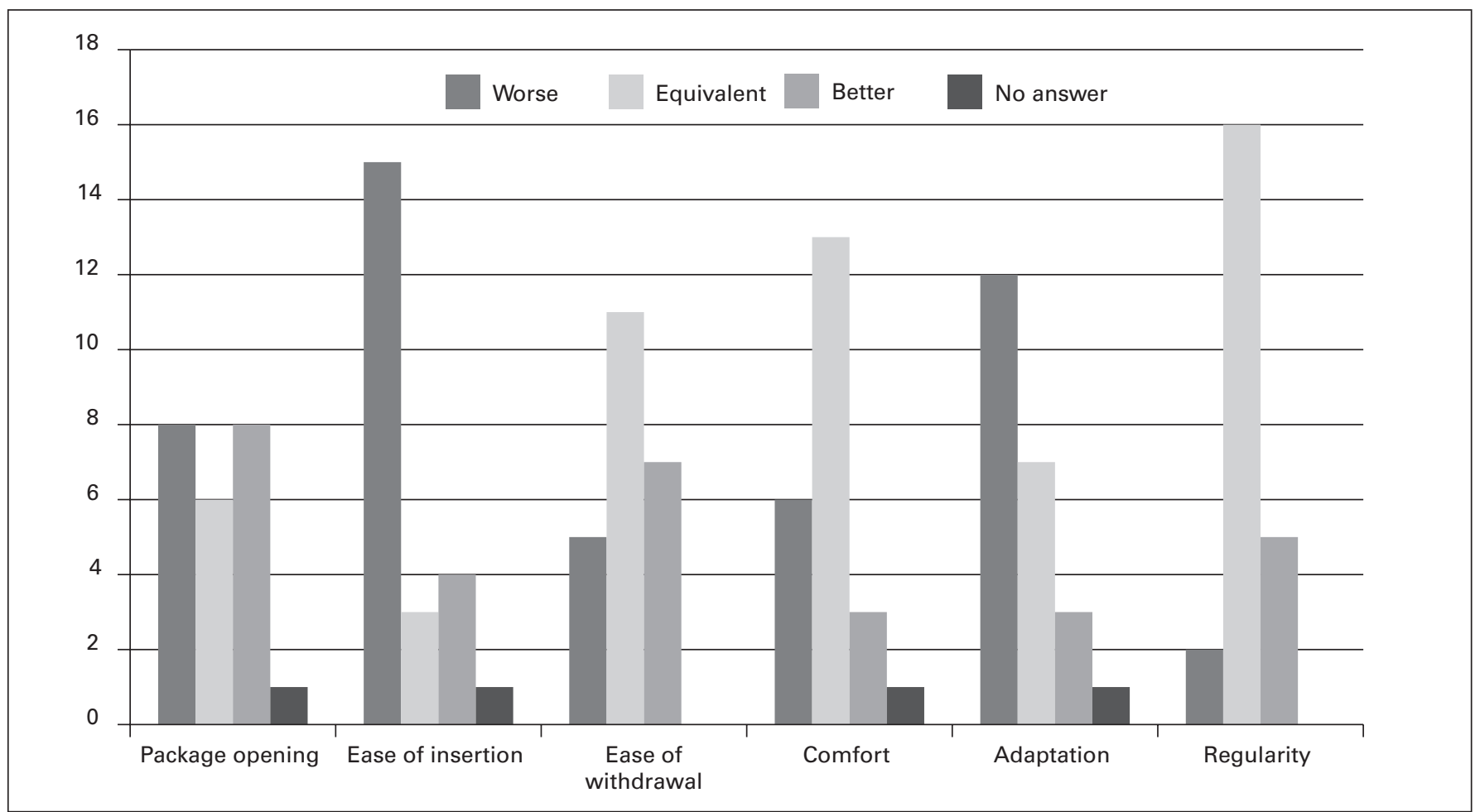

Fig. 3. Comparison of $\mathrm{HC}$ versus their usual product. Number of response to each question on 23 questionnaires.

\section{Discussion}

Previous studies showed that hydrophilic catheters produce less urethral irritation, ${ }^{3,4}$ provide better patient satisfaction ${ }^{3,4}$ and prevent urinary tract infection (UTI) more efficiently than the uncoated catheters. ${ }^{2}$ De Ridder and colleagues found that the number of spinal cord injury patients free of clinical UTI was doubled in the SpeediCath group compared to the plastic (PVC) group over a 1-year period. ${ }^{2}$ This study included only males over 16 years old and there was a high dropout rate $(46 \%)$. The efficacy of SpeediCath Compact was reported by Biering-Sprenson and colleagues. ${ }^{6}$ They concluded that there was no difference in the residual volume of urine after catheterization between the compact- $\mathrm{HC}$ and the standard-length female catheter, measured by ultrasound.

Unfortunately, HC is not reimbursed by Quebec governmental medical insurance. Only spinal cord injured patients recently obtained reimbursement from the governmental automobile insurance agency. The price difference between a $\mathrm{HC}$ and an uncoated catheter for a 1 -year use is major (with single-use catheterization, 5 times per day, it would cost about $\$ 8816$ per year for SpeediCath ${ }^{7}$ vs. $\$ 1916$ per year for Robinson-Nelaton $\mathrm{PVC}^{8}$ ). The $\mathrm{HC}$ is expensive for the patient and the family. It was important to find a target group in whom recommendations for using this catheter can be made until its reimbursement became widely accepted.

This present study showed that most respondents $(67 \%)$ preferred their uncoated catheter and would not change for the HC. Patients mostly criticized the difficulty to insert the HC. Patients had problems with the excess of lubricant (the catheter was too slippery). Also, the other comments were about the package; they found it difficult to open and the adhesive tape was not effective on every surface. The same results were found in the study by Taskinen and colleagues. ${ }^{5}$ In this study, the authors compared patient satisfaction for different HCs. They found no difference between the brands of catheters; although patients had their own preferences. Notwithstanding their results, we believe that our results cannot be extrapolated to other HCs because the manipulations between brands are different. Also, other companies do not have the compact version. The poor satisfaction of the $\mathrm{HC}$ can be explained by many factors. First, it could be argued that the population group studied is less open to change. Second, a 1-week trial could be considered too short for some patients; they may not have time to assess their satisfaction. Moreover, in this study, there was a major difference in the duration of the testing between patients ( 1 to 12 days). This could explain the poor rate for the adaptation criteria. Third, the anticipated higher price could negatively affect the respondents' interest to change brand of catheter. On the other hand, all the patients who tried the compact-HC would be ready to continue with this catheter even though it is the most expensive. They preferred this one because it is compact and clean. They did not have problem with the lubricant because this catheter has a longer dry 
Boucher et al.

\begin{tabular}{lc}
\hline \multicolumn{2}{l}{ Table 1. Characteristics of female patients on compact-HC } \\
\hline $\mathrm{Nb}$ on compact-HC & 8 \\
\hline $\mathrm{Nb}$ ready to change for compact-HC $(\%)$ & $8(100 \%)$ \\
\hline Mean age (years) & 14.5 \\
\hline $\begin{array}{l}\text { Participation in questionnaire } \\
\text { (filled in/telephone) }\end{array}$ & $4 / 4$ \\
\hline $\begin{array}{l}\text { Person who answered the questionnaire } \\
\text { (mother/children) }\end{array}$ & $1 / 7$ \\
\hline Self-ClC & 8 \\
\hline Intellectual deficit & 1 (mild) \\
\hline Impaired dexterity & 1 \\
\hline Spina bifida/spinal cord injury & $5 / 3$ \\
\hline HC= hydrophilic-coated catheters; ClC = clean intermittent catheterization. \\
\hline
\end{tabular}

handle in comparison with the long and short $\mathrm{HC}$ versions.

Biering-Sprenson and colleagues did not find a statistically significant difference in the overall satisfaction for the compact-HC compared to the reference catheters. ${ }^{6}$ However, patients only tried this compact catheter 3 times during a single day. The authors concluded that the compact catheter offers an alternative for women who depend on intermittent catheterization in their daily lives. It may influence the acceptance of $\mathrm{CIC}$ and thus compliance.

There was a high rate of incomplete questionnaires in our study. Half of the questionnaires were answered by the mothers who already had to spend many hours caring for their children. Even a small questionnaire is an additional workload for them. The questionnaires answered by phone could also introduce a bias to this study. Also, 4 of the 7 patients $(57 \%)$ who replied by phone would like to continue with SpeediCath and could have positively influenced our statistics, but this result is probably balanced by the 3 other patients.

Patients or their parents had the choice to exclude themselves from the 1-week trial if the one-time attempt during the clinic visit was not appealing to them. This created a selection bias toward more motivated families. Even though a high proportion of patients/parents did not find the initial attempt a positive experience, most of them were still interested in participating in the trial.

\section{Conclusion}

After a short trial period, most children preferred their uncoated catheter and would not change for the HC. However, female patients catheterizing per-urethra with a compact-HC were more likely to prefer its use over the uncoated catheters; the compact-HC could be offered to this population. It would be interesting to analyze the costbenefit and cost-effectiveness of the compact-HC compared to uncoated catheter in females.

Division of Urology, Centre Hospitalier Universitaire de Québec, Université Laval, Québec, QC

Acknowledgement: Coloplast Canada Corporation supplied catheters for free to the patients in this study.

Competing interests: None declared.

This paper has been peer-reviewed.

\section{References}

1. Lapides J, Diokno AC, Siber SM, et al. Clean intermittent self-catheterization in the treatment of urinary tract disease. J Urol 1972;107:458-61.

2. De Ridder DJMK, Everaert K, García Fernández L, et al. Intermittent catheterisation with hydrophilic-coated catheters (Speedicath) reduces the risk of clinical urinary tract infection in spinal cord injured patients: a prospective randomised parallel comparative trial. Eur Uro 2005;48:991-5.

3. Hedlund H, Hielmas K, Jonsson 0, et al. Hydrophilic versus non-coated catheters for catheterization. Scand J Urol Nephrol 2001;35:49-53.

4. Stensballe J, Looms D, Nielsen PN, et al. Hydrophilic-coated catheters for intermittent catheterisation reduce urethral micro trauma: a prospective, randomised, participant-blinded, crossover study of three different types of catheters. Eur Urol 2005;48:978-83.

5. Taskinen S, Fagerholm R, Ruutu M. Patient experience with hydrophilic catheters used in clean intermittent catheterization. J Pediatr Urol 2008;4:367-71.

6. Biering-Sorensen F, Hansen HV, Nielsen PN, et al. Residual urine after intermittent catheterization in females using two different catheters. Scand I Urol Nephrol 2007;41:341-5.

7. Guide des produits: soins d'incontinence et urologie, Coloplast; www.coloplast.ca (Accessed October 25, 2010).

8. Médi-Sélect Ltée. www.medi-select.ca (Accessed October 25, 2010).

Correspondence: Dr. Stéphane Bolduc, Centre hospitalier de l'Université Laval, 2705 boul. Laurier, Québec, QC GIV 4G2; sbolduc_2002@yahoo.ca 